\title{
FORMAS DE INTITULAR MINIFICCIONES
}

\section{Laura Elisa Vizcaíno Mosqueda}

Instituto de Investigaciones Bibliográficas, Universidad Nacional Autónoma de México lauravizcaino@filos.unam.mx

Resumen: El presente artículo estudia cuatro formas de titular relatos breves o minificciones: títulos con una mención genérica, títulos apócrifos, títulos que abarcan la totalidad del texto sin relato aparente, y títulos narrativos. Esta revisión permite afirmar que ese primer paratexto puede ser medular o imprescindible en el desarrollo del discurso. Aunque toda obra literaria otorga importancia a su título, en la brevedad se intensifica la relación, los títulos no son recursos externos o mera formalidad, sino que inciden en el mensaje de todo el texto. Dentro del marco conceptual, se entiende minificción como texto literario cuya narración puede ser explícita o implícita, por lo tanto, los ejemplos que serán empleados varían entre las historias convencionales y la extrema brevedad que solo deja huellas mínimas de la tradición del contar.

Palabras clave: minificción, títulos, géneros, convenciones literarias, paratexto.

\section{WAYS TO TITLE SHORT FICTIONS}

\begin{abstract}
This article studies four forms of titling short stories or minifictions: titles with a generic mention, apocryphal titles, titles that cover the entire text without an apparent story, and narrative titles. This review shows that this first paratext can be core or essential in the development of the discourse. Although every literary work attaches importance to its title, in short fictions this relationship intensifies, the titles are not external resources or mere formality, but instead they affect the message of the entire text. Within the conceptual framework, short fiction is understood as a literary text whose narration can be explicit or implicit, therefore, the examples that will be used vary between conventional stories and extreme brevity that only leaves minimal traces of the storytelling tradition.
\end{abstract}

Keywords: short fiction, titles, genres, literary conventions, paratext.

\section{DOI: $\underline{\text { https://doi.org/10.24029/lejana.2022.15.3555 }}$}

Recibido: el 4 de octubre de 2021

Aceptado: el 18 de enero de 2022

Publicado: el 25 de febrero de 2022 
La intención de revisar los títulos en la minificción surge al reflexionar sobre los géneros literarios, y cómo algunas de sus marcas se suelen anunciar en los títulos para influir en el modo de leer y ordenar bibliotecas. Esto después de la pregunta que me hizo un colega bibliotecólogo, ¿cómo clasificar un libro que anunciaba el título de "poesía", pero sin poemas en su contenido? Comprendí que los títulos, más allá de su carga semántica, son guías, ¿pero hacia dónde nos llevan? Cualquier tipo de lector, incluido un bibliotecario o un librero, necesita de los paratextos de los libros, entre ellos los títulos, para la recepción y disposición de las obras. Asimismo, en el estudio de los paratextos más comunes como las portadas, puede haber indeterminación sobre el contenido, pues no es su obligación señalar el género al que la obra se inscribe. Indeterminación que es llevada al extremo cuando se trata de títulos de literatura hiperbreve, los cuales pueden engañar sobre su contenido y replantear las convenciones lectoras.

En la disciplina bibliotecológica existen diversos rubros para estudiar el acceso a la información, un eje principal es la catalogación: ¿cómo clasificar? ¿Cómo ordenar el universo de la comunicación escrita? Por su parte, en los estudios literarios y en la práctica creativa, nadie piensa en los aprietos a los que se enfrentan los bibliotecólogos cuando una obra es híbrida en su contenido y en sus géneros de escritura. A pesar de la creación de etiquetas temáticas, muchos textos se escapan de las convenciones y proponen nuevas mezclas genéricas o bien nuevos géneros.

Desde la época de Aristóteles, ha existido la idea de delimitar a la literatura en géneros. Sin embargo y por suerte, muchas obras literarias se escapan de los cajones impuestos, y es esa misma libertad la que obliga a construir nuevas etiquetas, más allá de la épica y la dramática de la edad antigua. La teoría literaria, por su parte, se basa en el contenido de la obra para afirmar la inclusión en cierto género establecido por el canon y la tradición. Sin embargo, una biblioteca, por más moderna que sea, o una librería, por más experta que sea, al trabajar con cuantiosas cantidades de volúmenes, necesitan de los paratextos, sobre todo de los títulos, para ordenar y en consecuencia acercar al receptor, usuario o cliente a la lectura.

Cuando Gérard Genette define a la architextualidad se refiere a esta como el tipo de relación intertextual más abstracta de todas: "una relación completamente muda que como máximo articula una mención paratextual (títulos como en Poesías, Ensayos, Le Roman de la Rose, etc., o, más generalmente, subtítulos: la indicación Novela, Relato, Poemas, etc., que acompaña al título en la cubierta del libro), de pura pertenencia taxonómica" (1989: 13). Aunque el especialista los ubica entre paréntesis, los títulos serían de gran ayuda para distinguir un género. Sin embargo, para perjuicio de aquellos quienes se dedican a la clasificación, Genette también advierte que "el texto en sí mismo no está obligado a conocer, y mucho menos a declarar su cualidad genérica. La novela no se designa explícitamente como novela, ni el poema como poema" (1989: 13).

Ahora bien, aumentando los obstáculos para los bibliotecólogos, ¿qué tan confiables son los paratextos de la literatura? Genette solo señala que la mención paratextual puede acontecer de manera explícita o ausente dentro de los títulos de una obra. Mientras que en la literatura ese tipo de recursos funcionan como fenómenos lúdicos de los que no siempre es posible fiarse. Tanto en novelas, cuentos y en la narrativa hiperbreve, hay casos donde los títulos clarifican, pero también esconden, juegan y engañan. 
Aunado a lo anterior, hay una distinción entre el título de un libro compilatorio, como una antología, y aquellos títulos de textos contenidos en la misma. Lo cual recuerda que cada cuento, ensayo, relato, minificción son una obra en sí, aunque pueda estar contenida en un recipiente mayor. ${ }^{1}$ Estos casos no requieren de clasificación para ingresar a las bibliotecas, están resguardados dentro de una obra que los engloba, sin embargo, requieren otros cuestionamientos y observaciones en los que me detendré, pues tienen su propia autonomía.

En el caso de los títulos de minificciones, hay una relación más estrecha con el encabezado y el cuerpo del texto, en ocasiones inciden en el contenido, se diluyen sus límites, dejando de ser paratextos para convertirse en parte del texto. Mientras mayor es la brevedad, se hace imperante aprovechar cada recurso; cada elemento tiene su carga semántica y los títulos no se quedan atrás e incluso pueden llegar a ser parte del discurso completo.

A continuación, revisaré ciertas formas de intitular minificciones. Parto de la hipótesis de que en la literatura breve acontecen correspondencias o reciprocidades más cercanas entre título y cuerpo, en el sentido de que hay una conexión más inmediata entre paratexto y texto. No quiere decir que los géneros más extensos, como la novela o el teatro, no pongan atención a sus títulos, en la literatura cada elemento tiene su razón de ser. Sin embargo, la minificción adquiere la posibilidad de aprovechar la inmediatez y la brevedad a favor de textos lúdicos: que jueguen con los significados y transgredan los límites paratextuales. Por lo cual, dejaré de lado los títulos descriptivos comunes en cualquier narración y me centraré en cuatro tipos que considero tienen una mayor participación en el significado del discurso: los que mencionan un género, los apócrifos, los que son todo el relato y los narrativos.

Respecto a la literatura hiperbreve, utilizaré el término minificción por ser el que engloba a otras formas de la ficción breve. Se trata de una "supracategoría literaria poligenérica, un hiperónimo" (Andres-Suárez, 2010: 30), que puede contener desde prosa poética, microcuentos, hasta literatura corta con rasgos narrativos sugeridos. Sobre el carácter narrativo, que autores como David Roas o David Lagmanovich han señalado como características de estos tipos de escritura, conviene recordar la procedencia histórica del término "minificción" dentro de la revista El cuento y cómo evolucionó. Esta publicación periódica de larga tradición, convocaba a un concurso titulado "Concurso de cuentos de El cuento". Durante 1964 y 1965 se otorgaba como premio un automóvil y el reto constaba de escribir un cuento de 25 cuartillas. Para 1969, las dimensiones se modificaron drásticamente: el nombre cambió a "Concurso de cuento brevísimo", el premio consistía en mil pesos, la extensión mínima era de una línea y máxima de una cuartilla. Mientras que el ejemplo utilizado en cada convocatoria era "El Dinosaurio" de Augusto Monterroso. A su vez, cuando se comienzan a publicar los primeros textos ganadores, es que la revista de Edmundo Valadés abre la sección que lleva por nombre "Minificciones" y así comienza a utilizarse el término.

\footnotetext{
${ }^{1}$ También existen libros de narraciones breves que, a pesar de la autonomía de cada una, forman parte de un libro con un tema o personajes en común que los une. Por ejemplo, Caza de Conejos (1986) de Mario Levrero puede leerse como relatos autónomos o dependientes. Al respecto, Pablo Brescia y Evelia Romano se preguntan: “¿Cuáles son las operaciones de lectura que nos permiten (autorizan, indican, sugieren) leer un texto determinado como algo autónomo y, a la vez, leerlo como pieza integrante de otro texto, otro algo que lo contiene?" (Brescia-Romano, 2006: 7). Proponen el concepto "colección de textos integrados" para entender a aquellos que están unidos por un eje en particular e incluso, podrían considerarse novelas compuestas de fragmentos.
} 
Tomar en cuenta esta consideración histórica afina el marco conceptual de este trabajo pues por un lado precisa que las dimensiones no van más allá de una cuartilla, pero sobre todo nos recuerda una tradición que no sólo viene del género del cuento sino también de una historia de la lectura de la brevedad. Los intereses de escritura y consumo de ese cuento brevísimo se afinaron gracias a Edmundo Valadés y a la participación de autores de distintos países que publicaron en $E l$ cuento; actualmente, algunos de ellos son representativos para el género, como Luisa Valenzuela, Ana María Shua, Raúl Brasca, Agustín Monsreal, Pía Barros.

La relación de la minificción con el cuento no significa que sea un subgénero del mismo, su extrema brevedad lo lleva a tener sus propios mecanismos que lo distinguen; uno de ellos, aprovechar la posibilidad semántica de los títulos. Es decir, los aspectos que vemos en narrativas convencionales se intensifican en la minificción. Como menciona Lauro Zavala, "su naturaleza estética consiste en sintetizar, de manera alusiva, lo mejor de la tradición popular y lo más complejo de la sofisticación literaria" (2003: 14). Si bien, en la mayoría de las antologías de minificción se observa una mayor producción de textos con narrativas convencionales, también hay casos donde la narración queda mínimamente sugerida. Para esas posibilidades y por su cualidad abarcadora es que conviene el término minificción.

Ahora bien, ¿qué se entiende por paratexto y por qué prestarle atención? La metáfora utilizada por Gérard Genette, "umbrales", para referirse a las partes que rodean a la obra resulta ilustrativa. Pensar en el umbral de una casa como el equivalente a la portada de un libro, o el patio trasero como la contraportada o contratapa, le otorga la justa importancia al circuito literario, más allá del texto en sí. Concretamente, el paratexto es definido por Gérard Genette como "el acompañamiento de un cierto número de producciones, verbales o no, como el nombre del autor, un título, un prefacio, ilustraciones, que no sabemos ni debemos considerarlas o no como pertenecientes al texto, pero que en todo caso lo rodean y lo prolongan precisamente por presentarlo" (2001: 7).

Existen varias vetas de la teoría literaria con tendencias a analizar el texto y no siempre ha habido una costumbre por precisar los datos bibliográficos o paratextuales, a menos que se busque una historiografía o sociología de la literatura; considero que un análisis de los títulos no deja de señalar las tradiciones y contextos literarios. En el caso de la minificción, el trato con los títulos es lúdico, lo que replantea el modo de mirar la tradición de intitular y el modo de leer los encabezados. Los estudios de Genette aportan desde la teoría para que tratemos a los títulos con mayor atención, mientras que algunas minificciones, desde la práctica, permiten que el foco resida en ellos de manera más intensificada. Por ejemplo, es posible leer Simbad el Marino sin saber que pertenece a Las mil y una noches; pero en los textos hiperbreves, el título no solo acota nuestra mirada en un tema, sino que contribuye a la totalidad del discurso y el acercamiento con el lector resulta inmediato.

\section{Títulos con denominaciones genéricas}

Independientemente del género, el empleo de los títulos en la literatura ha evolucionado con el paso del tiempo y junto con la historia del libro. En la época antigua, los rollos de pergamino 
incluían el título al final y ni siquiera se trataba de títulos tan poéticos como La divina comedia, sino que únicamente hacían alguna referencia sobre su contenido. En El infinito en un junco, Irene Vallejo recuerda que "las listas de libros de las primeras bibliotecas de la historia, en el Oriente antiguo, mencionan las obras por su tema" (2021: 357). O bien eran títulos que copiaban la frase inicial del texto, pero no aportaban más información al respecto, se trataba más bien de encabezar y ordenar. Gracias al nacimiento de la imprenta, y la necesidad de controlar el comercio del libro es que muchos paratextos como el nombre del autor y el título de la obra requirieron mayor atención, tanto por sus creadores como distribuidores. Después del nacimiento y proliferación de la imprenta, la Santa Inquisición se enfrentó al problema de controlar la lectura y comercio del libro, pero ¿cómo prohibir cierta obra sin conocer su título? Por esta razón, con el fin de tener un mejor orden, impusieron una mayor exigencia de los elementos que debía contener la primera página, es decir, la portada, y fue entonces cuando el modo de intitular evolucionó.

Por su parte, mencionar el género de la obra en el mismo título es una práctica que comenzó con las piezas de teatro y después se replicó en otras literaturas; la precisión de comedias o sátiras fue una necesidad para ese ámbito. Mientras que "los otros géneros, y particularmente la novela, evitaban exhibir un status desconocido para los aristotélicos, y se las arreglaban para sugerir de una manera más indirecta, por medio de títulos paragenéricos de los que las palabras historia, vida, memorias, aventuras, viajes, y algunas otras más, formaban parte" (Genette, 2001: 84). Aunque esto no quiere decir que los autores no las reconocieran como novelas, más bien, esa etiqueta genérica se señalaba en otros paratextos como el prefacio.

Sobre esa tradición o necesidad de dar nombres a las obras con su marca de clasificación se inscriben las minificciones que señalan un género. Pero ¿cómo puede ser esto posible en textos tan breves? Y ¿cuál es su objetivo? Todas las razones apuntan a la cualidad lúdica de la brevedad: a decir, esconder y después desviar el sentido y silenciar.

Por un lado, están aquellas minificciones que anuncian otros géneros literarios distintos a los que realmente son. Tan solo en la antología mexicana Ficción atómica, publicada en el 2020 por la editorial Palíndroma, se aprecia un breve relato con el título "Cuento de hadas" (102), de Ricardo Sigala, cuyo contenido de cinco líneas desvirtúa el género mencionado, pues utiliza elementos comunes a los cuentos de hadas: una rana que debe ser besada por una princesa, pero el final acostumbrado se revierte cuando el narrador muerde las ancas del animal. Como consecuencia, el tipo de literatura tradicional anunciada al inicio se desvaloriza al tiempo que se homenajea con esta nueva versión.

De igual forma, en esta misma antología se encuentra "Final de novela" (137) de Dina Grijalva. Los finales de géneros extensos pueden ser tan breves como la misma minificción, y es lo que ocurre en este caso al rescatar o más bien reescribir el final de Madame Bovary, revirtiendo el suicidio del personaje y ubicando a la protagonista como una librera seductora. En el caso de Sigala y Grijalva, la mención de otro género nos ubica en cierto modo de lectura, mientras que el resultado no solo se opone a un cuento de hadas o a una novela, sino que también nos trae a la memoria esos géneros para desmitificarlos, los acerca para fracturarlos.

Por supuesto, existe el caso en que el título menciona al género al que sí corresponde. En la misma antología, Ficción atómica, se observa "Minicuento en su jugo" (73) de Amélie Olaiz, que 
recupera el formato de receta de cocina, pero no deja de ser un minicuento como se anuncia, aunque se acerca a los instructivos de preparación culinaria. De igual forma, cabe recordar una de las obras del argentino David Lagmanovich, Memorias de un microrrelato (2010): compendio de microrrelatos donde el género mismo es un personaje que cuenta su vida, desde su nacimiento hasta su muerte. Tanto en "minicuento" como en "memorias" se da la apariencia de cumplir con lo anunciado en el título, aunque su contenido resulte más bien una apropiación de las características comunes de esos tipos de escritura, como la autobiografía, que a su vez se mezclan con otros discursos para presentar nuevas versiones de los mismos.

Sobre los géneros y los juegos que realiza la minificción con ellos, no pueden faltar las menciones a lo extraliterario. No significa que no sean literatura, sino que su fuente proviene de tradiciones discursivas comunes. La antología Cortocircuito, publicada por la BUAP en 2017, está dedicada a este tipo de ejemplares. El objetivo del libro fue reunir minificciones o microrrelatos que se mezclaran con géneros extraliterarios, a lo que su compilador, Fernando Sánchez Clelo, le llamó "cortocircuito" para referirse a la unión de elementos antagónicos. Por esta razón, aunque no en su totalidad, muchos títulos anuncian el género discursivo al que pertenecen. Así contamos con "Entrevista" (24) de Adriana Azucena Rodríguez, "Recetas de la casa" (27) de Agustín Monsreal, "Anuncios clasificados" (32) de Alberto Sánchez Argüello, "Carta a mi cáncer" (35) de Alejandro Gómez, "Recado en el refrigerador" (155) de Samantha Vaquero, entre muchos más.

La mayoría de estos textos requieren anunciar el género al que se inscriben para justificar el molde que ocupan en el cuerpo del texto; es decir, hacer coincidir el título con el formato, aunque el discurso sea polisémico: sí una receta, pero también un texto literario. Los anuncios y avisos, por mencionar casos específicos, son alrededor de once en toda la antología, y para cumplir su cometido requieren de las frases comunes "Se busca" o "Se solicita". Y por supuesto, los finales rompen con la convención de anuncio común para entregarnos un híbrido lúdico. Por ejemplo, "Clasificados" de María de Lourdes Carbajal: "Se solicita espectro con uñas largas y aguzadas para rascar desquiciante comezón fantasma en mano amputada" (2017: 129). El título simula ser parte de una sección del periódico, ser parte de un género no literario, pero su carga semántica comunica en más de un sentido.

Si los textos carecieran de sus títulos, se perdería el modo de juego, pues no se sabría con qué otro género están dialogando. Por lo tanto, no solamente anuncian el molde en el que se inscriben, sino también responden a las convenciones marcadas por lo que comúnmente entendemos como anuncio clasificado.

Hasta aquí han salido a relucir los títulos de géneros que no corresponden con el texto, los que sí cumplen con el género anunciado, y la mención a los que están fuera de la literatura. En cada caso, cumplen con su función de enmarcar, como todo paratexto, pero también se convierten en imprescindibles del discurso en su totalidad, pues aportan al diálogo con el tratamiento genérico para anunciar nuevas versiones.

\section{Títulos apócrifos}


Los textos apócrifos conservan una tradición que se remonta a tiempos antiguos, como los documentos apócrifos de la Biblia o, dentro del mundo de la literatura, son notables las alusiones apócrifas en relación al Quijote. Se trata de elementos u obras completas que simulan ser parte de documentos verídicos o históricos, que juegan o aparentan ser piezas de archivo. En la ficción, el carácter apócrifo rompe los pactos de veracidad para retar sus propios límites. Como señala José María Merino respecto a este fenómeno, "el intento de invadir la realidad desde la ficción se hace aquí de forma opuesta, invadiendo la ficción desde la realidad" (2005: 86).

Uno de los elementos necesarios para construir un texto apócrifo es el paratexto: una nota al pie, un prefacio o por supuesto un título que pretendan enmarcar o resguardar un discurso fehaciente. Para señalar títulos apócrifos es importante que sea notoria la fractura de la veracidad. Si la minificción es lúdica y tiende a la ironía, es natural que los títulos escondan más información que la que solo se señala al inicio, pero en los apócrifos, además, se requieren elementos que demuestren la fractura de la veracidad.

El escritor mexicano Alberto Chimal tiende a jugar con los paratextos apócrifos para presentar textos que simulan ser documentos reales, esto sobre todo a partir de notas al pie que refieren a una supuesta definición enciclopédica. En su libro Gente del mundo (2014), se construyen referencias a comunidades y toda la obra en su totalidad, compuesta de textos breves, juega con la representación apócrifa.

Como ejemplos de títulos apócrifos en minificciones, conviene señalar los contenidos en dos libros de Agustín Monsreal: Los hermanos menores de los pigmeos (2004) y Los pigmeos vuelven a casa (2016), donde la mayoría de los textos están intitulados con los nombres de otros paratextos, por lo que se conforma la apariencia de veracidad. En el índice del ejemplar del 2004 se encuentran: "Primera dedicatoria", "Agradecimiento", "Prólogo inmediato", "Prólogo para después", "Prólogo final", "Aclaración no pedida", "Apunte autobiográfico" y "Segunda dedicatoria", entre otros más.

En la primera revisión de estos títulos se hace notorio un juego, casi burlón, respecto a ese tipo de textos umbrales que parecerían ser los primeros y únicos dentro de la obra, pero Monsreal demuestra que puede haber un "prólogo para después", o al inicio del inicio. Además de la mención paratextual que reta nuestras convenciones de lectores, pues ese tipo de elementos los solemos obviar e incluso esquivar por parecer menos importantes, se trata de títulos apócrifos que desacreditan su propia veracidad. Por ejemplo, en el título "Introducción a la séptima biografía autorizada, arbitraria e inconclusa de Agustín Monsreal" se hace referencia a un supuesto documento biográfico, rescatando el nombre del autor real, otro rasgo derivado del mismo apócrifo es el heterónimo: el apócrifo del yo o el nombre falso, el cual provoca una relación architextual entre el nombre anunciado como real y su misma fractura; fractura porque concretamente no se trata de la persona real, sino de su personaje homónimo.

Sin profundizar en la trama de los microrrelatos que componen los dos libros de Monsreal, tan solo prestando atención al índice, es notoria la influencia de Museo de la novela de la eterna (1967) de Macedonio Fernández, pues la estructura es similar: los paratextos comunes son tantos que el texto en sí parece que no va a comenzar nunca. En Los Pigmeos vuelven a casa, "Prefacio" aparece hasta la página 36 porque anteriormente hay diversos "prólogos", "dedicatorias" y demás 
introducciones. Dado que un índice es la guía de la obra, el que presentan los libros de Monsreal son un conjunto de títulos apócrifos que simulan ser esos elementos formales que rodean a la obra y se apegan a la verdad, para fracturar esa veracidad y en su lugar dejar mera ficción.

Como ocurre en el caso de la mención genérica, con los títulos apócrifos también hay un diálogo con las convenciones. Aunque un prólogo debería encontrarse en primer lugar, puede ocurrir que, con tantas formalidades en la disposición de un libro, los umbrales, detectados por Genette, estén postergados entre las dedicatorias y los prefacios. En conjunto, los dos libros de Monsreal exageran esas formalidades para burlarse de las mismas, pero a la vez, esto genera unidad. Si se tomara alguno de esos prólogos y se incluyera individualmente en una antología de varios autores, no perdería su significado, pero hay otro valor cuando lo leemos dentro del conjunto de los Pigmeos. Cada texto es autónomo, pero el orden y disposición en conjunto construye lo que convencionalmente promete un libro; el peso de los títulos (por ejemplo, "Segunda dedicatoria") es por el acomodo que se les da dentro de toda la obra.

\section{Títulos de relatos fantasmas}

El concepto de "relato fantasma" es acuñado por Aldo Flores, quien en el estudio introductorio de su antología Microfilmes en prosa (2021) distingue aquellos textos que tan solo constan de un título. La mención de un único elemento forma parte de las seis vertientes que Flores identifica en los microrrelatos. La primera de ellas consta de seis unidades: título, personaje, inicio, desarrollo, clímax y desenlace. A partir de estas, las combinaciones pueden irse reduciendo, hasta llegar a los casos donde solo el título es suficiente.

La idea se desprende del caso más citado: "El fantasma" de Guillermo Samperio, que enmarca un espacio en blanco. Este ni si quiera contiene una estructura sintáctica de sujeto, verbo y complemento, en su lugar está el silencio. De cualquier forma, el lector se encuentra frente a una composición discursiva y coherente, pues dentro del campo semántico de "fantasmas" la ausencia es un elemento clave.

La falta de texto narrativo se sostiene en las formas convencionales de narrar, estas están latentes en la mente del lector, incluso forman parte de su horizonte de expectativas, pero cuando la narración esperada se suspende, por una razón lógica como la no visibilización de un fantasma, lo esperado se fractura, pero se comprende. Esto no quiere decir que cualquier texto que tan solo conste de un título pueda funcionar de igual manera. En "El fantasma", si bien no hay narratividad, el recuerdo y quizás la nostalgia a la misma está presente. En "El fantasma", el título y el texto en blanco tienen una carga semántica capaz de anclarse en los relatos convencionales de fantasmas, además de que estos forman parte de una gran tradición literaria: están presentes en cuentos, novelas, leyendas y narraciones orales, por esta razón, la pequeña obra de Samperio puede resistir y sostenerse, aunque únicamente conste de dos palabras.

Asimismo, está el ejemplo de "Alzheimer" de Marcial Fernández, o como los destaca Aldo Flores: "Vampiro en el espejo" de Esteban Dublín, y "Lo que hallaron dentro de un cráneo de un policía después de la autopsia”, de Elías D’Alva. Ninguno de estos casos requiere de mayores 
explicaciones, se trata de mínimas unidades que así como encabezan también expresan con el silencio. El espacio en blanco es una ilustración que responde a los títulos.

Por supuesto que también existen casos donde lo que está ausente es el título y no el texto. En Permanente fugacidad, Adriana Azucena Rodríguez presenta un capítulo sobre los títulos y subtítulos en la minificción, donde destaca un aspecto posible de los géneros breves que es la ausencia del encabezado, "lo que resulta casi inaceptable en otros géneros" (2020: 52). Dentro de la minificción, la ausencia puede deberse a que el título del volumen basta para los textos incluidos: "En un recuento de volúmenes de minificciones sin título, se incluirían Crímenes ejemplares de Max Aub, Greguerías de Ramón Gómez de la Serna y, en proyectos creativos más recientes Cuentos malvados de Espido Freire o la serie Alfileres de Armando Alanís" (Rodríguez, 2020: 55).

A esta interesante lista agrego La sueñera (1984) de Ana María Shua, cuya ausencia de títulos por cada texto se suple con la enumeración. Sin embargo, cuando estos textos se insertan en antologías, los compiladores dan una propuesta de títulos: en la antología Relatos vertiginosos (2003), Lauro Zavala reúne ocho ejemplos del libro de Shua, a los cuales agrega el número original y el título que él considera para identificarlo. Mientras que en Por favor sea breve (2001), Clara Obligado omite el número y solo inserta un título derivado de la primera frase.

Aunado a estos casos, Javier Perucho nos recuerda que la anécdota es una de las formas breves provenientes de la tradición oral y antecedente directo del microrrelato y la minificción. "Importa resaltar que toda anécdota carece de título, rasgo de indistinción debido a su procedencia oral”, anónima y de uso público (2009: 19). Sin embargo, he dejado de lado los casos de ausencia de títulos porque se deben a que no hay necesidad de nombrar. En cuanto a los relatos fantasmas, la ausencia del texto y la importancia del título convierten a este último en discurso central, en discurso completo, así como en una parodia a la narrativa convencional. Nuevamente hay un desequilibrio en nuestras costumbres de lectores que nos alejan del "Había una vez" tradicional, pero nos obligan a poner el foco de atención en el espacio de los títulos e incluso en la tipografía, pues la hoja en blanco es necesaria para que estos títulos funcionen como tales y generen una expectativa que se completa con la ausencia.

\section{Títulos narrativos}

Los títulos narrativos son destacados por Genette en Umbrales. Un ejemplo ampliamente conocido, empleado por él es La muerte Iván Ilich, de la novela corta de León Tolstói, que en sí mismo ya está contando algo. Pero además de aquellos que insertan un verbo para accionar al sujeto, resultan curiosos los que son ampliamente extensos. Su curiosidad radica nuevamente en el diálogo con la tradición. Los títulos novohispanos y decimonónicos se caracterizan por una estructura sumamente larga. Tan es así que las primeras bibliografías resumían los títulos, práctica que actualmente es muy criticada y vetada de la disciplina bibliográfica. En los primeros libros impresos, las portadas estaban ocupadas por el gran espacio que requerían los títulos y, si acaso, el nombre del impresor. Pero debemos ser considerados con aquellos bibliógrafos que se enfrentaban a Doctrina cristiana breve y compendiosa por vía de diálogo entre un maestro y un discípulo, por mencionar un ejemplo (breve); no les quedaba más que resumir esos encabezados en sus catálogos. 
Dentro de la minificción contemporánea, resulta ya conocido el ejemplo de Luisa Valenzuela:

EL SABOR DE UNA MEDIALUNA A LAS NUEVE DE LA MAÑANA EN UN VIEJO CAFÉ DE BARRIO DONDE A LOS 97 AÑOS RODOLFO MANDOLFO TODAVÍA SE REÚNE CON SUS AMIGOS LOS MIÉRCOLES A LA TARDE

Qué bueno. (Valenzuela, 2008: 26)

A pesar de que el supuesto relato consta de dos palabras, considero conveniente citarlo como párrafo independiente, pues solo así podemos apreciar el juego de los silencios y el manejo de las convenciones lectoras, en las que nuestras costumbres parecen exigirnos un título de menor proporción en comparación con el contenido del relato. Esa tradición se invierte y nos exige mirar el título con mayor atención para conocer la narración de un personaje con nombre, edad y gustos culinarios. Dentro de este primer relieve que salta a la vista, también hay una problemática temporal que indica la hora en la que el protagonista come la medialuna (croissant) y el horario vespertino cuando visita el café de manera rutinaria, y todo esto acontece en el mismo espacio del encabezado.

Mientras tanto, el cuerpo del texto, en apariencia simple, no nos deja dudas del delicioso momento al probar bocado. Cada aspecto del texto de Valenzuela requiere un análisis detallado, pero el discurso en conjunto no solo pone el foco en lo narrado, sino también en la forma, en la disposición de recursos formales que manifiestan un cuestionamiento al modo de emplear comúnmente los títulos con sus respectivos relatos. Y este fenómeno es constante en la minificción y en la extrema brevedad: los elementos formales se hacen centrales; más que el deleite de Rodolfo Mandolfo, el texto nos habla del juego paratextual, de la posibilidad de invertir los roles entre título y contenido.

Un ejemplo más, aunque refiere al siglo Xx, pertenece a Augusto Monterroso, que al cumplirse 100 años de su nacimiento en el 2021, me parece debe ser releído:

MANUSCRITO ENCONTRADO JUNTO A UN CRÁNEO EN LAS AFUERAS DE SAN BLAS, S.B., DURANTE LAS EXCAVACIONES REALIZADAS EN LOS AÑOS SETENTA EN BUSCA DEL LLAMADO COFRE, O FILÓN

Algunas noches, agitado, sueño la pesadilla de que Cervantes es mejor escritor que yo; pero llega la mañana y despierto. (Monterroso, 1998: 187)

Este microrrelato está compilado en el libro La letra e (1987) junto con otros textos de títulos similares, como "Epitafio encontrado en el cementerio Monte Parnaso de San Blas, S.B"; donde vuelve a aparecer Cervantes y algunos otros escritores que, a diferencia de este, sí están sepultados efectivamente en el cementerio de Montparnasse. Ahora bien, la mención a San Blas y al autor del Quijote se debe a que en 1979, ocho años antes de la publicación de La letra e, Augusto Monterroso publicó la novela Lo demás es silencio, con Eduardo Torres como protagonista-escritor, quien habitó en San Blas y era experto en Shakespeare y Cervantes. Por lo tanto, toda la información contenida en el título crea un vínculo intertextual con ese protagonista representativo en la obra de Tito. Mientras que el juego irónico también se plantea en la alusión a Cervantes, cuyos restos no se han podido encontrar de manera certera. Por lo que el manuscrito aludido junto a un cráneo refiere sutilmente a la dudosa ubicación. 
Aunque no contáramos con esa información sobre las demás obras de Monterroso, este ejemplo también podría considerarse muestra de los títulos apócrifos vistos más arriba, que con elementos de la realidad pretenden ser veraces para después contradecir esa misma posibilidad. El espacio geográfico de una ciudad y la fórmula o molde del relato histórico que consiste en un título extenso, la alusión a un manuscrito antiguo e incluso la ambigüedad entre cofre o filón, delinean la dudosa autenticidad histórica que se suma al contenido lúdico donde el protagonista presenta su propia crítica.

Ahora bien, no todos los títulos deben ser extensos para considerarse narrativos. Dado que la narración puede estar sugerida, los nombres propios que pertenecen a obras representativas encapsulan la historia. Tal es el caso de "Penélope", "Medusa", "Aracne", "Afrodita" o "María Antonieta"; todos títulos contenidos en el libro Bellas de sangre contraria (2009) de Lilian Elphick, volumen que reescribe la historia de estos personajes con relatos breves y empleando esos encabezados nominales. La simple mención onomástica ya remite a narrativas míticas y beneficia la brevedad, pues exime la explicación de protagonistas y contextos. ${ }^{2}$

Aunque la novela Ulises de James Joyce comprende un extenso contenido, el título por sí solo comprime gran cantidad de información. En el espacio hiperbreve, la posibilidad de encapsular un hipotexto no solo beneficia a la brevedad, también demuestra que la relación intertextual requiere de un nombre para que la historia se despliegue en nuestra memoria de lectores. La onomástica puede narrar cuando refiere a otras historias y, si se ubica en el título, funciona para acotar la situación y para contar por sí misma. Este modo requiere de la intertextualidad y de competencias lectoras que reconozcan a los personajes de otras historias para comprender su reescritura. Un nombre propio basta para contarnos un relato cuando proviene de una tradición de historias, adquiere el poder de encapsular, resumir y por lo tanto le conviene a la minificción por su brevedad. Entonces, los títulos narrativos pueden ser tan extensos y detallados como los de Valenzuela y Monterroso, pero también breves como "Don Quijote" de Rogelio Guedea, cuyo nombre detona la evocación de toda una historia. ${ }^{3}$

\section{Conclusiones}

Como indica Adriana Rodríguez, "difícilmente se podría afirmar que el microrrelato se caracteriza por un particular empleo del título" (2020: 57). En efecto, existen muchos textos breves que no enfatizan ese elemento inicial y no es una cualidad intrínseca del género. Mientras que cada obra, sin importar su extensión, tiene su propia forma de concebir su encabezado. Los cuatro casos aquí estudiados se salen del tratamiento convencional de intitular; además, cada uno de ellos puede estar entrelazado: los títulos de relatos fantasmas no dejan de ser narrativos, y los que son narrativos pueden contener alusiones a textos apócrifos y estos a su vez pueden necesitar menciones genéricas. Como sea, indican un peso más grande que lo comúnmente identificable en un título

\footnotetext{
2 Sobre los nombres propios en la minificción puede consultarse: Laura Elisa Vizcaíno (2015): "El nombre como economía de sentido". Ritmo. Imaginación y crítica (Colegio de Ciencias y Humanidades), 27: 48-62.

${ }^{3}$ En Juan Armando Epple (comp.) (2005): Microquijotes. Barcelona, Thule.
} 
descriptivo, mientras que su cualidad contundente y de resumen los hace ser recursos útiles para abrevar en la minificción.

Es precisamente el uso convencional del título el que se pone sobre la mesa para cuestionarlo. Al ser un elemento cotidiano en la comunicación escrita, y a veces necesario para generar un orden en índices o catálogos, puede ser aprovechado en su totalidad para comunicar, pero también para replantear sus usos tradicionales. Lo que ocurre es que en la minificción no solo importa lo que se cuenta o la anécdota, sino también la evidencia de recursos formales, por esta razón, el modo de intitular expresa que nuestras costumbres lectoras pueden desafiarse con otras variaciones.

Mencionar el aspecto lúdico en el tratamiento de los títulos refiere a una situación pragmática que acontece en el lector. Por ello se ha insistido en el replanteamiento de nuestras costumbres lectoras. No quiere decir que estas formas de intitular sean novedosas o que marquen un precedente que anule a las anteriores, sino más bien hay una convivencia entre el homenaje y la crítica al pasado: una parodia a la tradición discursiva y a los títulos de una costumbre tácita.

Ahora bien, estos cuatro tipos de intitular también podrían encontrarse en otros géneros, pero lo que los distingue en la minificción es la inmediatez para relacionar título con cuerpo del texto: el espacio es tan corto que inmediatamente se genera la conexión entre ambas unidades. Además, forman parte de todo el relato, no como algo externo, sino interno; es decir, se convierten en indispensables para el entendimiento en conjunto. La minificción tiene la exigencia de aprovechar cada uno de los elementos textuales o discursivos para condensar información. Por esto, los títulos adquieren una responsabilidad mayor: se intensifica su utilidad expresiva y se aprovecha su cualidad de resumen que por sí mismos tienen. Mientras más se denote el modo de emplearlos —ya sea resaltándolos o revirtiendo su uso_-, más se aprecia su cualidad imprescindible.

Imagino que quien se dedique a la clasificación de libros en una biblioteca o su ordenamiento en una librería se enfrenta a distintos obstáculos, pero en la práctica ya habrá podido conocer lo fascinante que son los títulos; mientras que quienes estudiamos a la minificción observamos la utilidad de intitular para comprimir significados y beneficiar la contundencia de la literatura breve, pues cada título, sin importar al género al que pertenezca, encierra un discurso dispuesto a desplegarse.

\section{Bibliografía}

ANDRES-SUÁREZ, Irene (2010): El microrrelato español. Una estética de la elipsis. Palencia, Menoscuarto.

Brescia, Pablo-Evelia Romano (coords.) (2006): El ojo en el caleidoscopio. México, UNAM.

Chimal, Alberto (2014): Gente del mundo. México, Era.

ELPHICK, Lilian (2009): Bellas de sangre contraria. Santiago, Mosquito.

FlORES, Aldo (2021): "Prólogo. Las seis unidades de contenido y las seis vertientes en el microrrelato". En --- (comp.): Microfilmes en prosa. Cartelera de brevedades sobre cine. Perú, Quarks: 11-26. 
Gallegos, Juan Carlos (comp.) (2020): Ficción atómica. México, Palíndroma.

Genette, Gérard (1989): Palimpsestos. Madrid, Taurus.

--- (2001): Umbrales. México, Siglo XXI.

LagmanOvich, David (2010): Memorias de un microrrelato. Buenos Aires, Macedonia.

MERINO, José María (2005): “Los límites de la ficción”. Revista Anthropos, 208: 82-91.

Monsreal, Agustín (2004): Los hermanos menores de los pigmeos. México, Ficticia.

--- (2016): Los pigmeos vuelven a casa. México, Ficticia.

Monterroso, Augusto (1998): La letra e. Fragmentos de un diario. Madrid, Alfaguara.

Perucho, Javier (2009): Dinosaurios de papel. El cuento brevísimo en México. México, Ficticia.

RodríGUEZ, Adriana Azucena (2020): Permanente fugacidad. Ensayos sobre minificción. México, Universidad Autónoma Metropolitana-Azcapotzalco.

SÁnChez Clelo, Fernando (comp.) (2017): Cortocircuito. Fusiones en la minificción. Puebla, Benemérita Universidad Autónoma de Puebla.

VAllejo, Irene (2021): El infinito en un junco. La invención de los libros en el mundo antiguo. México, Penguin Random House.

VALENZUELA, Luisa (2008): Juego de villanos. Barcelona, Thule.

Zavala, Lauro (2003): Relatos vertiginosos. Antología de cuentos mínimos. México, Alfaguara.

(C) Laura Elisa Vizcaíno Mosqueda

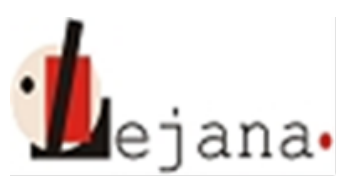

http://ojs.elte.hu/index.php/lejana

Universidad Eötvös Loránd, Departamento de Estudios Hispánicos

1088 Budapest, Múzeum krt. 4/C 